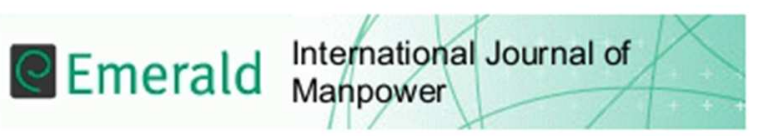

\title{
Do gender differences in career aspirations contribute to Sticky Floors?
}

\begin{tabular}{|r|l|}
\hline Journal: & International Journal of Manpower \\
\hline Manuscript ID & IJM-10-2015-0171.R2 \\
\hline Manuscript Type: & Research Paper \\
\hline Keywords: & Gender, Promotion, Preferences, Lab experiment \\
\hline
\end{tabular}

\footnotetext{
SCHOLARONE ${ }^{\text {Ix }}$

Manuscripts
} 


\title{
Do gender differences in career aspirations
}

\section{contribute to Sticky Floors?}

\begin{abstract}
Purpose - This study tests hypotheses regarding the importance of employee preferences in explaining Sticky Floors, the pattern that women are, compared to men, less likely to start to climb the job ladder.
\end{abstract}

Data/methods - We use original data obtained using a survey and a vignette study in which participants had to score the likeliness with which they would accept job offers with different promotion characteristics.

Findings - The main findings are that female young professionals have a less pronounced preference for more demanding and less routinary jobs and that this effect is mediated by the greater risk aversion and anticipated gender discrimination among women. No gender differences were found in the relative likeliness to apply for jobs that involve a promotion in terms of job authority.

Limitations - The vignette method assumes that artificial settings with low stakes do not bias results. Another limitation follows from the focus on interorganizational promotions among young professionals, which raises the question to what extent the results can be generalized to broader settings.

Originality/value - This article contributes to the literature on gender differences in careers by measuring the impact of employee preferences on gender differences in career decisions. 


\section{Introduction}

The higher strata of career ladders and work hierarchies continue to be dominated by men in most countries (Arulampalam, Booth, \& Bryan, 2007; Olivetti \& Petrongolo, 2008; World Economic Forum, 2014). Although occupational segregation and gender gaps in education and labor market participation have been strongly reduced - or even reversed in some cases - the vertical segregation of the sexes in the workforce appears to be more persistent. Illustrative of this situation is the percentage of women in company boards or in CEO positions, which remains far below the overall share of women in the employed labor force (Blau, Simpson, \& Anderson, 1998; World Economic Forum, 2014). One of the reasons for vertical segregation is the glass ceiling, which is the set of promotion barriers located at the upper rungs of the corporate ladder (Cotter, Hermsen, Ovadia, \& Vanneman, 2001).

Promotion barriers may, however, also be located at the lower career levels. The concept of sticky floors refers to a situation in which women are, compared to men, less likely to start to climb career ladders (Bjerk, 2008). There is a growing literature on the sticky floors phenomenon (Baert, De Pauw, \& Deschacht, 2016; Biagetti \& Scicchitano, 2011; Christofides, Polycarpou, \& Vrachimis, 2013; Manning \& Swaffield, 2008). It is important to study promotions, rather than career levels, because gender differences in the labor market are relatively small in the early years after labor market entry, while gender gaps in wages and career levels widen over the life-cycle (Adda, Dustmann, \& Stevens, forthcoming; 
Manning \& Swaffield, 2008; Bertrand, Goldin, \& Katz, 2010). So, theories that explain gender differences in career levels, should also be able to explain differences in career progression (promotion). Early-career obstacles are important because they may propagate into later career phases (eventually contributing to glass ceilings). Bjerk (2008) argues that career delays early on may cause many women not to have sufficient time to develop the success record at mid-level jobs required for promotion to the top jobs in the economy.

From a policy perspective it is important to understand the antecedents of vertical sex segregation and gender promotion gaps. The traditional approach to understanding gender differences in labor market outcomes has been to focus on factors such as employer discrimination and gender differences in human capital and family constraints (Altonji \& Blank, 1999). More recently, however, there has been an increasing interest in explanations related to employees' psychological attributes and preferences (Azmat \& Petrongolo, 2014; Azmat \& Ferrer, forthcoming; Bertrand, 2011; Bowles, Gintis, \& Osborne, 2001; Fortin, 2008; Heckman, Stixrud, \& Urzua, 2006; Reuben, Sapienza, \& Zingales, 2015). One example is the role of risk preferences: since women are more risk averse than men, women may tend to avoid job-related risks such as job-loss risk or earnings volatility, which are often associated with higher career levels (Azmat \& Petrongolo, 2014). Another example concerns the role of work versus home/family preferences: if men are more career-centered, have stronger work identities or if they find status-based career satisfiers more important compared 
with family-related satisfiers, then men will have stronger preferences for promotions (Greenhaus, Peng, \& Allen, 2012; Hakim, 2011).

A number of gaps remain in the literature on the relation between preferences and gender differences in careers. First, there is a large body of literature on gender differences in preferences (for a review, see Croson \& Gneezy, 2009) but it remains unclear to what extent these gender differences in preferences explain gender differences in careers (Bertrand, 2011). After all, the fact that lab experiments suggest that men and women differ in terms of some theoretically relevant psychological attributes (say, risk preferences), does not imply that these differences are important to explain labor market behavior and actual career outcomes. A second gap concerns the role of expected discrimination. In their review article on preferences and women's careers, Azmat and Petrongolo (2014) emphasize that anticipated gender discrimination might feed back into individuals' choices and that more research is needed on this topic. A third gap relates to the heterogeneity in career levels and promotions - an aspect that has been overlooked in much of the research on gender and promotions. A career level is an abstract concept which is determined by many concrete aspects or dimensions, including pecuniary rewards, prestige, task complexity, responsibilityand job authority (Slocum, 1974). For example, some jobs offer high wages but little job authority (and vice-versa). The literature suggests that men and women appreciate these aspects in different ways: men supposedly attach greater value at objective outcomes such as money, while women value things like feelings of accomplishment and interpersonal relationships (Konrad, Ritchie, 
Lieb, \& Corrigall, 2000). A career hierarchy is thus a multidimensional rank order, in which upward mobility (promotions) can take place along a particular dimension or a combination of these dimensions. Little is known about the extent to which men and women focus on various types of promotions and about the extent to which gender differences in preferences explain these patterns.

In this study we contribute to the aforementioned recent literature by empirically testing whether gender differences in employee preferences translate into gender differences in career decisions and thereby contribute to the existence of sticky floors. To this end, we present a vignette study in which participants have to score the likeliness with which they would accept job offers with different promotion characteristics. In addition, they are surveyed on a number of preferences and attitudes. By means of this research design, we are able to address the gaps mentioned above.

\section{Theoretical framework}

Prior research has shown that women advance at slower rates in their careers than men and found evidence for the sticky floors phenomenon (Baert et al., 2016; Biagetti \& Scicchitano, 2011; Bjerk, 2008; Blau \& Devaro, 2007; Christofides et al., 2013; Manning \& Swaffield, 2008). At the same time, scholars increasingly emphasize the role of preferences to explain the career patterns of women and men (Azmat \& Petrongolo, 2014; Bertrand, 2011). If this preference theory of 
gender career gaps is correct, then gender differences in preferences should also result in a difference in the extent to which men and women want to be promoted. The main gender differences in preferences that have been reported in the literature relate to risk and work preferences (Bertrand, 2011). Because the literature suggests that men have stronger risk preferences (Croson \& Gneezy, 2009) and stronger work preferences (Greenhaus et al., 2012; Hakim, 2011), the following hypotheses are formulated for this study.

Hypothesis 1a. Men are more focused than women on making promotion in terms of job content.

Hypothesis $\mathbf{1 b}$. Men are more focused than women on making promotion in terms of job authority.

These hypotheses distinguish between two dimensions of careers. Hypothesis 1a refers to a career advancement in terms of job content, which is the general degree of task complexity, occupational level and responsibilities associated with the job. Most of the empirical research (Booth, Francesconi, \& Frank, 2003; Månsson, Elg, \& Jonnergård, 2013) operationalizes promotions along this dimension of careers. Differences in job content do not refer to horizontal differences, such as sectors or areas of expertise, but to vertical differences in task complexity and job demands, so that job content is a dimension along which promotions can take place. Hypothesis $1 \mathrm{~b}$ refers to job authority, another dimension of careers which is defined as the extent to which a job involves power over the work of others. More concretely, job authority may refer to either 
supervising over the work of others, deciding on the organization of the work of others or deciding on who is to be hired, fired or promoted (Smith, 2002). Various studies report gender gaps in workplace authority levels (Yaish \& Stier, 2009) and suggest that the promotion rates along the authority dimension are lower for women than for men (Hachen, 1990). Job authority is an important career dimension to take into account in studies of gender career gaps because it is somewhat orthogonal to the other career dimensions: some countries, such as Sweden, combine high levels of gender equality in terms of earnings and home responsibilities with a very large gender gap in workplace authority (Rosenfeld, Van Buren, \& Kalleberg, 1998). However, the relation between gender, preferences, and job authority is not straightforward because job authority by definition also involves the social aspect of working with other employees. Evidence suggests that women have stronger social preferences (Croson \& Gneezy, 2009) and that women have other interpersonal styles than men because they are more concerned with others (Eagly \& Johnson, 1990). The social aspect of jobs involving job authority, such as team leadership positions, has a positive effect on the likeliness of women to apply for such jobs. Therefore, the effect that men are more focused than women on a promotion because of stronger risk and work preferences (hypothesis 1) will be partially or entirely offset in the case of authority promotions. This brings us to a second research hypothesis.

Hypothesis 2. The gender effect for promotions in terms of job authority is smaller than the gender effect for promotions in terms of job content. 
If the hypotheses $1 \mathrm{a}$ and/or $1 \mathrm{~b}$ are supported by the empirical evidence, then the question arises whether the observed difference in the focus of men and women on promotions, can be explained by gender differences in preferences and attitudes. The literature indicates that men have stronger risk preferences (Croson \& Gneezy, 2009) and stronger work preferences (Fortin, 2008; Hakim, 2011; Greenhaus et al., 2012). Other determinants are gender differences in work/family preferences and conflicts between the work and family domains that are reportedly detrimental to careers (Hoobler et al., 2010), as well as the aforementioned theory that anticipated gender discrimination feeds back into individuals' choices (Azmat \& Petrongolo, 2014). Women anticipate greater discriminatory career barriers than men (McWhirter, 1997). This results in the following hypotheses.

Hypothesis 3a. Gender differences in risk preferences partly explain the stronger focus of men on promotions, both in job content and job authority.

Hypothesis 3b. Gender differences in work (versus family) preferences partly explain the stronger focus of men on promotions, both in job content and job authority.

Hypothesis 3c. Gender differences in anticipated gender discrimination partly explain the stronger focus of men on promotions, both in job content and job authority. 


\section{Research model}

In principle, employees may attain a higher career level via two channels: either by being hired into entry-level jobs and then progress to upper-level positions along well-defined career ladders (intra-organizational promotions) or by being hired directly into these higher positions from outside the organization (interorganizational promotions). This distinction is relevant for gender promotion gaps. Research suggests that women face less obstacles to promotion via the internal channel than via external hiring (Lyness \& Judiesch, 1999), possibly because more information is available about the performance of internal women so that sex stereotypes become less important in the case of intra-organizational promotions. In this study the attractiveness of jobs will be measured by presenting job vacancies to participants and by measuring the likeliness that participants will apply for these vacancies, so the focus is on the external promotion channel. This choice is defendable as this external channel is important in many professions, such as academia, and even more so as the traditional organizational career makes place for the boundaryless career in which employees increasingly cross organizational boundaries (Arthur \& Rousseau, 2001).

Figure 1 presents the research model this study uses to test the hypotheses. In this model, the career level of a job is assumed to be associated with the likeliness to apply for that job, but that relation is moderated by gender. This gender moderation effect is in turn mediated by preferences (mediated moderation). 
Figure 1. A mediated moderation model of gender, employee preferences and promotions

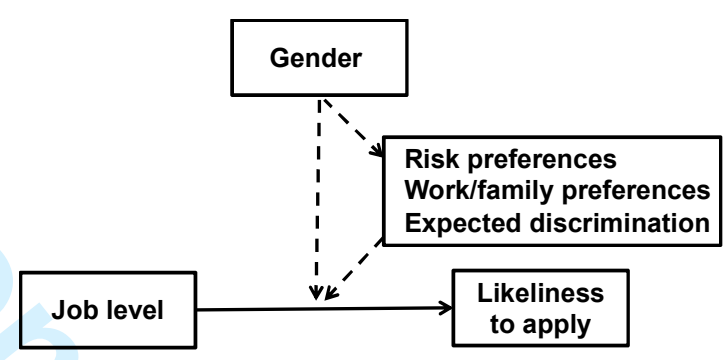

\section{Method}

\subsection{Participants}

Undergraduate students from business economics programs at a WesternEuropean University participated in the experiment $(\mathrm{N}=622)$ in May 2014. The participants were assigned to the experimental conditions using systematic random sampling (the first participant was presented vignette 1, the second participant vignette $2, \ldots)$. Thereafter they had to fill out a questionnaire. The data were collected on paper copies. No other data than those presented in the current study were gathered from the participants. A lottery incentive involving 30 euro gift vouchers was used to increase the motivation of the participants and the response rate. In the end, only 10 participants had to be excluded from the sample because of non-response. 
The validity of using student subjects ultimately depends on whether the subjects are representative for the population of interest in terms of the effect of interest. For example, research indicates that using students to study the decisions of experienced managers may produce bias (Cooper, 2006) while no bias has been found in settings where the subject-population distance is smaller (Depositario et al., 2009; Druckman \& Kam, 2011). In our study the population of interest contains early-career professionals, so our identifying assumption is that the relation between gender and career preferences among students in business economics is the same as among early-career professionals.

\subsection{Materials and procedure}

Vignettes (scenarios) were used to study the extent to which employee preferences contribute to sticky floors. All the versions included the same description of the role the participants were supposed to assume in the experiment:

You currently work as an accountant in a firm that offers accounting services to customers. Your responsibility within the team is to process invoices and to prepare VAT returns, monthly and yearly financial statements and budgets. You started working in this position after graduating from university and you have now been working there for about 5 years. Your daily commute to work is around 20 minutes. You have a family with two young children and your partner is highly educated and has a busy job. 
This role was essentially that of an early-career professional working in a job involving no supervision over others (low job authority) and corresponding to a level 3 or 4 of the International Standard Classification of Occupations (relatively low job content). The International Standard Classification of Occupations (ISCO) is an International Labor Organization classification tool for organizing jobs into groups according to the tasks and duties undertaken in the job and is often used to study stratification, social mobility and promotions (Baerts, Deschacht, \& Guerry, 2011; Ganzeboom \& Treiman, 1996).

In all the versions the participants were told that they were being contacted by a recruitment agency that offered them one of the jobs described in the vacancies presented in Figure 2. The vignettes were job vacancies constructed by manipulating two independent variables: the promotion dimensions 'job authority' and 'job content'. A between-subjects design was used, so each of these vacancies was presented to one quarter of the survey sample. 
Figure 2. Four vignettes corresponding to $2 \times 2$ job level aspects

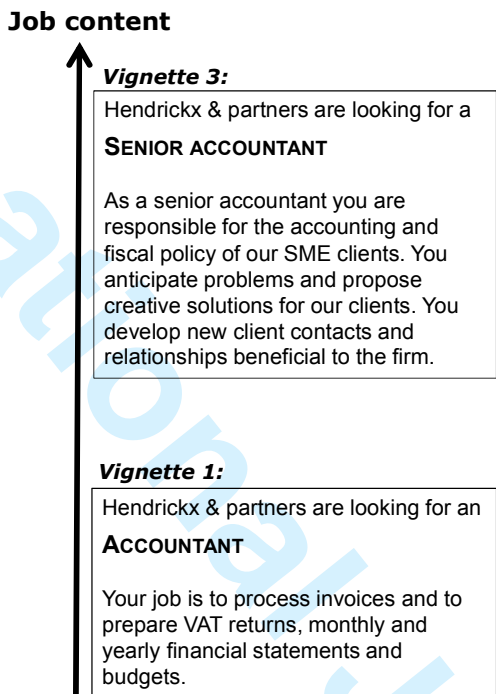

Vignette 4:

Hendrickx \& partners are looking for a SENIOR Accountant / TEAM LEAdER

As a senior accountant you are responsible for the accounting and fiscal policy of our SME clients. You anticipate problems and propose creative solutions for our clients. You develop new client contacts and relationships beneficial to the firm.

You coordinate the work of a team of 12 accountants. You are responsible for the training, recruitment and evaluation of team members.

Vignette 2:

Hendrickx \& partners are looking for an AcCOUNTANT / TEAM LEADER

Your job is to process invoices and to prepare VAT returns, monthly and yearly financial statements and budgets.

You coordinate the work of a team of 12 accountants. You are responsible for the training, recruitment and evaluation of team members.

Vignettes 2 and 4 refered to jobs with higher levels of job authority than those in Vignettes 1 and 3 because they ask for a team leader supervising other employees. Vignettes 3 and 4 involved a higher job content than vignettes 1 and 2 because they referred to higher occupational levels, requiring skills to meet more complex duties. The job content in Vignettes 3 and 4 was constructed in such a way that it corresponded to occupational level 2 ('Professionals') in the ISCO, whereas Vignettes 1 and 2 corresponded to the lower ISCO-levels 3 or 4 ('Associate professionals' or 'Clerical support workers'). Vignette 1 had the same content and authority level as the currently held job (in the role description). 


\section{Measures}

The participants were asked whether they accepted an invitation for a job interview, using a rating scale ranging from 1 ('Certainly not') to 7 ('Yes, certainly'). This rate measured the likeliness to apply for the proposed job and forms the dependent variable in this study. Demographic information on gender, age and exam results was collected as well to check that the participants were randomly assigned to the vignettes.

All the participants completed a post-experimental questionnaire in which a number of preferences and attitudes were measured using the following scales:

- Risk preferences. Two subscales of three items each were selected from the Domain-Specific Risk-Taking Scale and combined (Blais \& Weber, 2006) to measure social and financial risk preferences. These two domains were considered to be the most relevant for labor market behavior. Respondents are asked to indicate the likelihood with which they would engage in activities such as 'Speaking your mind about an unpopular issue in a meeting at work' or 'Investing 5\% of your annual income in a very speculative stock'. Cronbach's alpha-coefficient was 0.58 . Although alpha is below the common 0.7 treshold we include it in the analysis because we do not see this as evidence against the reliability, let alone validity, of the measure. The relatively low value of alpha in this case is partly explained by the limited number of items in the scale (alpha is negatively related to the number of items). More importantly, we are 
perfectly willing to admit that risk preferences have different aspects resulting in some heterogeneity among the items. We agree with Streiner (2003) here that bigger alpha's are not always better because unidimensional concepts can sometimes have different aspects that are only modestly correlated, but which are nevertheless usefull to measure as a whole (after all, it is quite easy to inflate alpha values by duplicating items through asking the same question in many different ways).

- Expected discrimination is measured using a four-item scale (Foley, Hang-Yue, \& Wong, 2005) in which respondents are asked to what extent they agree with statements such as 'My gender has a negative influence on my career advancement' and 'At work, many people have gender stereotypes and treat me as if they were true'. Cronbach's alpha-coefficient was 0.83 .

- Work-home preferences. Three scales were used for work-home preferences. Two six-point scales measure Work-to-Life (WTL) conflict and Life-to-Work (LTW) conflict (Carlson, Kacmar, \& Williams, 2000) in which respondents are asked to what extent they agree with statements such as 'My work will keep me from my family activities more than I would like' (WTL) or 'I have to miss work activities due to the amount of time I must spend on family responsibilities' (LTW). Cronbach's alpha-coefficients were 0.50 and 0.35 respectively. The third scale assessed Work-versus-home priority by asking respondents to place themselves on a 5-point scale in which 1 represented 'primarily family' and 5 represented 'primarily work' (Carlson \& Kacmar, 2000). 


\section{Analysis and results}

\subsection{Random assignment and manipulation checks}

In order to check for potential non-randomness in the assignment process, F-tests were performed to check that the means of eight demographic variables and measuring scales did not differ across the four experimental conditions. Table 1 presents the results and shows that none of these differences were significant.

Table 1. Random assignment checks

\begin{tabular}{|c|c|c|c|c|c|c|}
\hline & Vignette 1 & Vignette 2 & Vignette 3 & Vignette 4 & $\mathbf{F}$ & $\mathbf{p}$ \\
\hline 1. Gender: female & 0.52 & 0.57 & 0.58 & 0.53 & 0.51 & .672 \\
\hline 2. Age & 19.1 & 19.3 & 19.3 & 19.3 & 0.38 & .766 \\
\hline 3. Exam scores & 3.49 & 3.64 & 3.47 & 3.51 & 0.63 & .594 \\
\hline 4. WTL conflict & 2.53 & 2.54 & 2.50 & 2.52 & 0.25 & .860 \\
\hline 5. LTW conflict & 2.23 & 2.26 & 2.27 & 2.30 & 0.93 & .428 \\
\hline 6. Priority: work & 2.38 & 2.36 & 2.37 & 2.41 & 0.12 & .946 \\
\hline 7. Risk aversion & 3.98 & 3.94 & 4.10 & 3.95 & 1.15 & .330 \\
\hline 8. Expected discrimination & 2.43 & 2.54 & 2.45 & 2.52 & 0.48 & .693 \\
\hline Observations & 157 & 158 & 153 & 153 & & \\
\hline
\end{tabular}

To test whether the manipulations were perceived by the participants in the way they were intended by the researchers, the participants were asked to rate on a 7point scale the extent to which the job described in the vacancy represented a higher level of job content, a higher level of job authority and - in general - a promotion. The results presented in Table 2 show that job offers involving either a higher occupational level or authority level were perceived as such. A related 
question is whether both promotion dimensions were understood as representing different dimensions of promotions. The results indicate that some confounding occurs - manipulating only job authority (Vignette 2) tends to increase the perceived job content as well (from 2.9 to 4.4) and vice-versa - but the confounding effects are smaller than the effects on the perceived dimension of the intended manipulation.

Table 2. Manipulation checks

\begin{tabular}{|c|c|c|c|c|c|c|}
\hline & Vignette 1 & Vignette 2 & Vignette 3 & Vignette 4 & $\mathbf{F}$ & $\mathbf{p}$ \\
\hline Perceived higher content & 2.9 & 4.4 & 5.0 & 5.3 & 90.0 & $p<.001$ \\
\hline Perceived higher authority & 3.0 & 5.9 & 4.7 & 5.8 & 168.1 & $\mathrm{p}<.001$ \\
\hline Perceived promotion & 3.0 & 5.0 & 4.9 & 5.2 & 90.2 & $\mathrm{p}<.001$ \\
\hline Observations & 157 & 158 & 153 & 153 & & \\
\hline
\end{tabular}

\subsection{The moderating effect of gender}

Participants who were offered a job implying a promotion had a higher mean likeliness to apply for this job $\left(F_{(3,616)}=19, p<.001\right)$ : the mean in the Vignette 1 (low job content, low job authority) is only 4.8 as opposed to $5.5,5.8$ and 5.9 in Vignettes 2 (low job content, high job authority), 3 (high job content, low job authority) and 4 (high job content, high kob authority) respectively. In order to analyze the moderating effect of gender on this effect of offered job level, the mean likeliness to apply was analyzed using a 2 (gender) $\times 2$ (high job content or not) $\times 2$ (high job authority or not) independent measures ANOVA. The results 
presented in Table 3 show significant main effects of job content $\left(F_{(1,612)}=38.87\right.$, $p<.001)$ and job authority $\left(F_{(1,612)}=9.43, p<.01\right)$. The main effect of gender is not significant. More importantly, a significant interaction was found between gender and job content $\left(F_{(1,612)}=6.88, p<.01\right)$. In contrast, the interaction between gender and job authority is not significant.

Table 3. Analysis of variance

\begin{tabular}{lllll}
\hline & Sum of squares (SS) & df & Mean SS & $\mathrm{F}$ \\
\hline Gender: female $(G)$ & 0.03 & 1 & 0.03 & 0.02 \\
Job content: higher $(C)$ & 64.47 & 1 & 64.47 & $38.87^{* * *}$ \\
Job authority: higher $(\mathrm{A})$ & 15.64 & 1 & 15.64 & $9.43^{* *}$ \\
$G \times C$ & 11.41 & 1 & 11.41 & $6.88^{* *}$ \\
$G \times A$ & 0.95 & 1 & 0.95 & 0.57 \\
$C \times A$ & 17.09 & 1 & 17.09 & $10.31^{* *}$ \\
$G \times C \times A$ & 0.29 & 1 & 0.29 & 0.17 \\
Residual & 1015.07 & 612 & 1.66 & \\
\hline Total & 1122.90 & 619 & 1.81 & \\
\hline$* \mathrm{p}<.05, * * \mathrm{p}<.01, * * * \mathrm{p}<.001$. & & & &
\end{tabular}

Figure 3 illustrates the main results graphically by means of interaction plots. The difference in mean likeliness to apply between equal and higher level job offers is larger for men than for women. This applies to both the dimensions of job content and job authority, although in the latter case the difference is not significant (see Table 3 for the significance tests concerning these effects). 
Figure 3. Gender moderation in the effect of job level on likeliness to apply

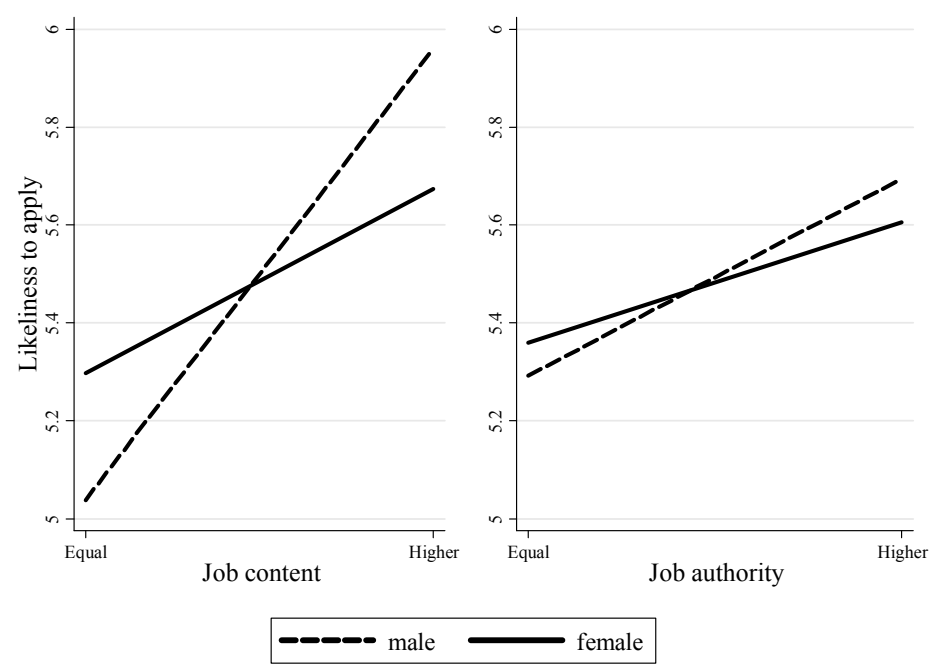

\subsection{The mediating effect of preferences}

In order to test whether the gender moderation of the effect of occupational level (job content level) on likeliness to apply for the proposed job is mediated by the preferences and attitudes mentioned earlier (see Measures), a mediated moderation analysis was performed using the procedure proposed by Muller, Judd and Yzerbyt (2005). This approach applies mediation analysis to moderator effects. In the usual logic of mediation analysis, if a variable $M$ mediates the effect of a variable $X$ on $Y$ then there is an indirect effect of $X$ on $Y$ via $M$ (Hayes, 2009) or, equivalently, the direct effect of $X$ on $Y$ (holding $M$ constant) is smaller in absolute value than the total effect of $X$ on $Y$ (not holding $M$ constant). Similarly, a moderator effect $X$ is said to be mediated by $M$ if holding constant additional 
moderator variables $M$ reduces the effect size of the moderator effect of $X$ (Muller et al., 2005).

Table 4 compares the preferences of the male and female participants in our experiment. The gender differences are significant for the measures of risk aversion and expected gender discrimination. The female participants expected more gender discrimination in their future jobs $(M=2.96, S D=0.93)$ than men ( $M$ $=1.90, S D=0.68)\left(t_{(612)}=15.8, p<.001\right)$ and they are more risk averse $(M=4.20$, $S D=0.80)$ than men $(M=3.77, S D=0.79)\left(t_{(608)}=6.2, p<.001\right)$. There are no significant gender differences for the other measures. The question is now to what extent the gender differences in preferences - those relating to risk aversion and expected discrimination - explain the fact that the male participants are more likely to apply for a job involving a higher occupational level.

Table 4. Gender differences in preferences (mean comparisons)

\begin{tabular}{lllll}
\hline & Women & Men & Gender difference & $\mathrm{t}$ \\
\hline WTH Conflict & $2.50(0.47)$ & $2.55(0.48)$ & -0.06 & 1.45 \\
HTW Conflict & $2.24(0.38)$ & $2.29(0.39)$ & -0.05 & 1.47 \\
Priority: work & $2.35(0.69)$ & $2.42(0.74)$ & -0.07 & 1.36 \\
Risk aversion & $4.20(0.80)$ & $3.77(0.79)$ & 0.43 & $6.20 * * *$ \\
Expected discrimination & $2.96(0.93)$ & $1.90(0.68)$ & 1.06 & $15.80^{* * *}$ \\
\hline$*$ p<.05; $* *$ p<.01; *** $p<.001$. & & &
\end{tabular}

The results of the mediated moderation analysis are presented in Table 5. Model (1) is the base model in the analysis and repeats the results found earlier in the ANOVA and interaction plot: a significant interaction of gender and job content $(b=-0.576, S E=0.211, p<.01)$. The estimated coefficient implies that the effect 
of offering a higher content job on the predicted likeliness to apply is 0.576 points lower for women than for men. In the models (2) and (3) the potential mediating factors are added one at a time. The extent to which these factors are in fact mediating the gender moderation, can be seen in the reduction (in absolute value) of the effect of the gender-promotion interaction term. In model (2) the estimated effect is reduced to 0.504 , suggesting that there is some mediation by risk preferences. In model (3), which evaluates the mediating effect of expected gender discrimination, the estimated coefficient is further reduced to 0.411 . Although this reduction represents only between one third and one quarter of the overall moderating effect in the base model, the estimated coefficient in model (3) is no longer significant, which is indicative for "full mediation". In this instance this means that the gender moderation in the effect of job level on likeliness to apply is fully mediated by gender differences in expected discrimination. This result does not follow from a mere correlation between gender and expected discrimination because a re-estimation of model (3) for the female subsample only (results are available upon request) produced an even greater estimated coefficient, in absolute value, of the interaction term $(-0.183$ instead of -0.173$)$. The combined mediating effect of the two factors is evaluated in model (4), in which case the estimated effect is reduced to 0.324 or almost 50 percent of the overall moderating effect in the base model. Models (5) and (6) re-estimate models (1) and (4) by controlling for exam scores to investigate the role of how male and female students are selected into university programmes in business economics. The mean exam score of the females in the sample (3.61) is slightly 
above that of the male subjects $(3.42, \mathrm{t}=2.04, p<0.05)$, which might indicate that males and females self-select differently into these programmes. However, holding exam scores constant hardly changes the coefficients of interest and leads to identical conclusions: gender moderates the effect of job content on the likeliness to apply (model 5) and this effect is mediated by the greater risk aversion and anticipated gender discrimination among women (model 6).

Table 5. Mediated moderation (OLS regressions on the likeliness to apply)

\begin{tabular}{|c|c|c|c|c|c|c|}
\hline & $\begin{array}{c}(1) \\
b /(S E)\end{array}$ & $\begin{array}{c}(2) \\
b /(S E)\end{array}$ & $\begin{array}{c}(3) \\
b /(S E)\end{array}$ & $\begin{array}{c}(4) \\
b /(S E)\end{array}$ & $\begin{array}{c}(5) \\
b /(S E)\end{array}$ & $\begin{array}{c}(6) \\
b /(S E)\end{array}$ \\
\hline \multirow[t]{2}{*}{ Gender: female } & 0.289 & 0.244 & 0.261 & 0.208 & 0.465 & 0.384 \\
\hline & $(0.148)$ & $(0.155)$ & $(0.180)$ & $(0.188)$ & $(0.346)$ & $(0.366)$ \\
\hline \multirow[t]{2}{*}{ Promotion: higher job content } & $0.942^{* * *}$ & $1.528^{* *}$ & $1.283^{* * *}$ & $1.910^{* *}$ & $0.925^{* * *}$ & $1.870^{* *}$ \\
\hline & $(0.156)$ & $(0.533)$ & $(0.290)$ & $(0.603)$ & $(0.156)$ & $(0.600)$ \\
\hline \multirow[t]{2}{*}{ Gender $x$ Promotion } & $-0.576^{* *}$ & $-0.504^{*}$ & -0.411 & -0.324 & $-0.557^{* *}$ & -0.329 \\
\hline & $(0.211)$ & $(0.220)$ & $(0.252)$ & $(0.261)$ & $(0.210)$ & $(0.260)$ \\
\hline \multirow[t]{2}{*}{ Risk aversion ( $\mathrm{R})$} & & 0.112 & & 0.115 & & 0.116 \\
\hline & & $(0.094)$ & & $(0.094)$ & & $(0.093)$ \\
\hline \multirow[t]{2}{*}{ Promotion $\times \mathrm{R}$} & & -0.151 & & -0.161 & & -0.166 \\
\hline & & $(0.134)$ & & $(0.135)$ & & $(0.134)$ \\
\hline \multirow[t]{2}{*}{ Expected discrimination (D) } & & & 0.024 & 0.030 & & 0.016 \\
\hline & & & $(0.089)$ & $(0.090)$ & & $(0.089)$ \\
\hline \multirow[t]{2}{*}{ Promotion $\times \mathrm{D}$} & & & -0.173 & -0.179 & & -0.156 \\
\hline & & & $(0.128)$ & $(0.129)$ & & (0.129) \\
\hline \multirow[t]{2}{*}{ Exam score } & & & & & 0.090 & 0.084 \\
\hline & & & & & $(0.061)$ & $(0.062)$ \\
\hline \multirow[t]{2}{*}{ Gender x Exam score } & & & & & -0.060 & -0.056 \\
\hline & & & & & $(0.088)$ & $(0.090)$ \\
\hline \multirow[t]{2}{*}{ Constant } & $5.021^{* * *}$ & $4.589^{* * *}$ & $4.976^{* * *}$ & $4.525^{* * *}$ & $4.735^{* * *}$ & $4.282^{* * *}$ \\
\hline & $(0.109)$ & $(0.372)$ & (0.199) & $(0.419)$ & $(0.240)$ & $(0.471)$ \\
\hline R-square & 0.07 & 0.07 & 0.07 & 0.07 & 0.07 & 0.07 \\
\hline $\mathrm{N}$ & 620 & 610 & 614 & 608 & 618 & 606 \\
\hline
\end{tabular}

${ }^{*} \mathrm{p}<.05 ;{ }^{* *} \mathrm{p}<.01 ;{ }^{* * *} \mathrm{p}<.001$. 


\section{Discussion}

The research results presented in the former section suggest that female young professionals are less likely than their male counterparts to apply for jobs implying a promotion in terms of job content (Hypothesis 1a). The difference in mean likeliness to apply between jobs of equal and higher occupational level jobs, is significantly greater for men than for women. The implication is that career aspirations and occupational preferences contribute to sticky floors and vertical sex segregation.

The results also indicate that the various career aspects (or promotion dimensions) interact in different ways with the career aspirations of men and women. The moderating effect of gender for promotions in terms of job authority was found to be much smaller (and non-significant) than the effect for promotions in terms of job content (Hypothesis 1b; Hypothesis 2). This finding is in line with our a priori expectations that a female preference for taking up team leadership because of its social aspect, partially offsets (and even suppresses) the general effect that men are more likely to apply for a job involving a promotion. However, the experiment did not unequivocally show that this hypothesized channel is in fact responsible for the observed finding that the gender moderation is significant when promotions are defined in terms of occupational levels and not when they are defined in terms of supervisory job authority. This certainly is an issue worth considering in further research. 
Finally, the experiment indicates that the effect of gender and job content is itself to a large extent mediated by gender differences in preferences (Hypothesis 3 ). The mediation effect of expected discrimination is substantial (H3b), that of workhome preferences is negligible $(\mathrm{H} 3 \mathrm{c})$ and that of risk aversion is of intermediate effect size (H3a). The results of this mediation analysis should be interpreted with care, because the mediating factors were observed - rather than randomly assigned - among the participants in the experiment. One possible interpretation of these findings is that the impact of gender on the likeliness to apply is caused by the perceived gender discrimination and greater risk aversion among young women. But we cannot exclude the possibility of reverse causality (for example when less aspiring women perceive more gender discrimination) or omitted variables in the mediation analysis.

Can the outlined results be explained by extreme response bias? Although the literature on the relation between gender and extreme responding shows mixed results (Van Vaerenbergh \& Thomas, 2013), the present study does find evidence that female participants are more likely to avoid using the endpoints of rating scales than male participants. For example, among those in Vignette 4 (high job level - high job authority) only 22 percent of the women chose the top endpoint answer 7 ('Yes, certainly') as opposed to 36 percent of the men. In order to test the robustness of our results to this gender difference in response styles, the models in Table 5 were re-estimated by adding the number of extreme responses of each participant as an additional control variable (De Jong, Steenkamp, Fox, \& Baumgartner, 2008). For each participant the number of endpoint responses was 
counted among all 30 items of the measures. ${ }^{1}$ In each of the five models the reestimated coefficient of the gender moderation effect slightly increased, but there were no changes in terms of significance (results are available upon request). This suggests that neither the results on gender moderation, nor those on preference mediation can be explained by extreme responding bias.

This study had some limitations. The vignette method assumes that artificial settings with low stakes do not bias results. It is not impossible that in real-life, where the stakes are higher, women would apply for the high level jobs they declined in the experiment. However, bias would only arise if men and women react differently to artificial settings. Another limitation follows from the focus on inter-organizational promotions among young professionals, which raises the question to what extent the results can be generalized to broader settings, also including intra-organizational promotions. However, the distinction between inter- and intra-organizational promotions is less important in this study because, unlike studies of employer discrimination where statistical discrimination and stereotypes are involved, employee preferences relate to jobs in general rather than whether those jobs are within the organization or not. Finally, the experiment does not exclude the possibility that work commitment and aspirations change over the course of the career in response to real-life experiences and go on to play a larger role as careers develop. Neither does it rule out the role of competing explanations in terms of human capital, family

\footnotetext{
${ }^{1}$ The mean percentage of extreme responses among the male participants (25.5\%) was significantly greater $\left(t_{(619)}=2.98, p=0.003\right)$ than among the female participants $(21.0 \%)$.
} 
obligations or employer discrimination, which might all be contributing simultaneously to the sorting of men and women into career levels. This experiment only shows that these competing explanations alone are not sufficient to explain patterns of vertical sex segregation.

In conclusion, this experiment shows that employee preferences contribute to vertical sex segregation in terms of job content - even among young professionals. This suggests that aiming for a fifty-fifty gender balance in every job may not be welfare improving, although it is hard to say what such a balance should be as long as it is unclear to what extent preferences, compared to productivity and discrimination, translate into gender imbalances in the labor market. Organizations and policymakers who try to reduce gender imbalances should be aware of the way career aspects interact in different ways with gender and that job-related risk and expected discrimination reduce the likeliness of women to apply for jobs in the upper rungs of career ladders. In order to increase the pool of female applicants, recruiters could emphasize the social aspects of higher level jobs. A clear policy of equal opportunities might reduce expected discrimination and so encourage female candidates. As a final point, the creation of stable work environments - where earnings volatility, relative compensation and job-loss risk are limited - are also likely to contribute to gender equality in the workplace. 


\section{References}

Adda, J., Dustmann, C., \& Stevens, K. (forthcoming). The career costs of children. Journal of Political Economy.

Altonji, J., \& Blank, R. (1999). Race and gender in the labor market. In: O. Ashenfelter \& D. Card (Eds.). Handbook Of Labor Economics, Vol 3 (pp. 3143-3259). Amsterdam: Elsevier.

Arthur, M., \& Rousseau, D. (2001). The boundaryless career as a new employment principle. In: M. Arthur \& D. Rousseau (Eds.). The boundaryless career (pp. 3-20). Oxford: Oxford University Press..

Arulampalam, W., Booth, A., \& Bryan, M. (2007). Is there a glass ceiling over Europe? Exploring the gender pay gap across the wage distribution. Industrial and Labor Relations Review, 60(2), 163-186.

Azmat, G., \& Petrongolo, B. (2014). Gender and the labor market: What have we learned from field and lab experiments?. Labour Economics, 30, 32-40.

Azmat, G., \& Ferrer, R. (forthcoming). Gender gaps in performance: Evidence from young lawyers. Journal of Political Economy.

Baert, S., De Pauw, A.-S., \& Deschacht, N. (2016). Do employer preferences contribute to Sticky Floors?. Industrial \& Labor Relations Review, 69(3), 714-736.

Baerts, A., Deschacht, N., \& Guerry, M.-A. (2011). The role of the partner in promotions to top positions in Belgium. European sociological review, 27(5), 654-668.

Bertrand, M. (2011). New perspectives on gender. In: O. Ashenfelter \& D. Card (Eds.). Handbook Of Labor Economics, Vol $4 B$ (pp. 1543-1590). Amsterdam: Elsevier.

Bertrand M., Goldin, C., Katz, L. (2010). Dynamics of the gender gap for young professionals in the financial and corporate sectors. American Economic Journal: Applied Economics. 2010:2 (3), 228-255.

Biagetti, M., \& Scicchitano, S. (2011). A note on the gender wage gap among managerial positions using a counterfactual decomposition approach: sticky floor or glass ceiling? Applied Economics Letters, 18(10), 939-943.

Bjerk, D. (2008). Glass ceilings or sticky floors? Statistical discrimination in a dynamic model of hiring and promotion. The Economic Journal, 118(530), 961-982.

Blais, A.-R., \& Weber, E. (2006). A domain-specific risk-taking (DOSPERT) scale for adult populations. Judgment and Decision Making, 1, 33-47.

Blau, F., \& Devaro, J. (2007). New evidence on gender differences in promotion rates : An empirical analysis of a sample of new hires. Industrial Relations, 46(3), 511-550.

Blau, F. , Simpson, P., \& Anderson, D. (1998). Continuing progress? Trends in occupational segregation in the United States over the 1970s and 1980s. Feminist Economics, 4(3), 29-71.

Booth, A., Francesconi, M., \& Frank, J. (2003). A sticky floors model of promotion, pay, and gender. European Economic Review, 47(2), 295-322.

Bowles, S., Gintis, H., \& Osborne, M. (2001). The determinants of earnings: A behavioral approach. Journal of Economic Literature, 39(4), 1137-1176.

Carlson, D., \& Kacmar, K. (2000). Work-family conflict in the organization: Do life role values make a difference? Journal of Management, 26(5), 1031-1054.

Carlson, D., Kacmar, K., \& Williams, L. (2000). Construction and initial validation of a multidimensional measure of work-family conflict. Journal of Vocational Behavior, 56(2), 249-276.

Christofides, L., Polycarpou, A., \& Vrachimis, K. (2013). Gender wage gaps, 'sticky floors' and 'glass ceilings' in Europe. Labour Economics, 21, 86-102. 
Cooper, D. (2006). Are experienced managers experts at overcoming coordination failure?. Advances in Economic Analysis \& Policy, 5(2), 1-52.

Cotter, D., Hermsen, J., Ovadia, S., \& Vanneman, R. (2001). The glass ceiling effect. Social Forces, 80(2), 655-681.

Croson, R., \& Gneezy, U. (2009). Gender differences in preferences. Journal of Economic Literature, 47(2), 1-27.

De Jong, M., Steenkamp, J., Fox, J., \& Baumgartner, H. (2008). Using item response theory to measure extreme response style in marketing research: A global investigation. Journal of marketing research, 45(1), 104-115.

Depositario, D., Nayga, R., Wu, X., \& Laude, T. (2009). Should students be used as subjects in experimental auctions?. Economics Letters, 102(2), 122-124.

Druckman, J., \& Kam, C. (2011). Students as experimental participants: A defense of the 'narrow data base'. In: J. Druckman, D. Green, J. Kuklinski, \& A. Lupia (Eds.). Cambridge handbook of experimental political science (pp. 41-57). New York: Cambridge University Press.

Eagly, A., \& Johnson, B. (1990). Gender and leadership styla: A meta-analysis. Psychological Bulletin, 108(2), 233-256.

Foley, S., Hang-Yue, N., \& Wong, A. (2005). Perceptions of discrimination and justice: Are there gender differences in outcomes? Group \& Organization Management, 30(4), 421-450.

Fortin, N. (2008). The gender wage gap among young adults in the United States: The importance of money versus people. Journal of Human Resources, 43(4), 884-918.

Ganzeboom, H., \& Treiman, D. (1996). Internationally comparable measures of occupational status for the 1988 International Standard Classification of Occupations. Social Science Research, 25(3), 201-239.

Greenhaus, J., Peng, A., \& Allen, T. (2012). Relations of work identity, family identity, situational demands, and sex with employee work hours. Journal of Vocational Behavior, 80(1), 27-37.

Hachen, D. (1990). Three models of job mobility in labor markets. Work and Occupations, 17(3), 320-354.

Hakim, C. (2011). Women's lifestyle preferences in the 21st century: implications for family policy. In G. Beets, J. Schippers, \& E. te Velde (Eds.). The future of motherhood in Western societies (pp. 177-195). Dordrecht: Springer.

Hayes, A. (2009). Beyond Baron and Kenny: Statistical mediation analysis in the new millennium. Communication Monographs, 76(4), 408-420.

Heckman, J., Stixrud, J., \& Urzua, S. (2006). The effects of cognitive and noncognitive abilities on labor market outcomes and social behavior. Journal of Labor Economics, 24(3), 411-482.

Hoobler, J., Hu, J., \& Wilson, M. (2010). Do workers who experience conflict between the work and family domains hit a "glass ceiling?": A meta-analytic examination. Journal of Vocational Behavior, 77(3), 481-494.

Konrad, A., Ritchie Jr, J., Lieb, P., \& Corrigall, E. (2000). Sex differences and similarities in job attribute preferences: a meta-analysis. Psychological bulletin, 126(4), 593641.

Lyness, K., \& Judiesch, M. (1999). Are women more likely to be hired or promoted into management positions? Journal of Vocational Behavior, 54(1), 158-173.

Manning, A., \& Swaffield, J. (2008). The gender gap in early-career wage growth. The Economic Journal, 118 (530), 983-1024.

Månsson, J., Elg, U., \& Jonnergård, K. (2013). Gender-based career differences among young auditors in Sweden. International Journal of Manpower, 34(6), 572-583. 
McWhirter, E. (1997). Perceived barriers to education and career: Ethnic and gender differences. Journal of Vocational Behavior, 50(1), 124-140.

Muller, D., Judd, C., \& Yzerbyt, V. (2005). When moderation is mediated and mediation is moderated. Journal of Personality and Social Psychology, 89(6), 852-863.

Olivetti, C., \& Petrongolo, B. (2008). Unequal pay or unequal employment? A crosscountry analysis of gender gaps. Journal of Labor Economics, 26 (4), 621-654.

Reuben, E., Sapienza, P., \& Zingales, L. (2015). Taste for competition and the gender gap among young business professionals. Working paper. Columbia University.

Rosenfeld, R., Van Buren, M., \& Kalleberg, A. (1998). Gender differences in supervisory authority: Variation among advanced industrialized democracies. Social Science Research, 27(1), 23-49.

Slocum, W. (1974). Occupational careers: A sociological perspective. Chicago: Aldine.

Smith, R. (2002). Race, gender and authority in the workplace: Theory and research. Annual Review of Sociology, 28, 509-542.

Streiner, D. (2003). Starting at the beginning: An introduction to coefficient alpha and internal consistency. Journal of personality assessment, 80(1), 99-103.

Van Vaerenbergh, Y., \& Thomas, T. (2013). Response styles in survey research: A literature review of antecedents, consequences, and remedies. International Journal of Public Opinion Research, 25(2), 195-217.

World Economic Forum (2014). The global gender gap report 2014. Geneva: World Economic Forum.

Yaish, M., \& Stier, H. (2009). Gender inequality in job authority: A cross-national comparison of 26 countries. Work and Occupations, 36(4), 343-366. 


\section{Revision 2 of Manuscript IJM-10-2015-0171 | Response to Reviewer \#2}

We thank the reviewer for the additional comments and suggestions. In this document, one can find a systematic account of how we responded to each of these comments and suggestions. The referee's original comments are in italics and shaded in grey.

In general I am satisfied with the changes introduced in the paper but I still have some related requests/comments.

1) The results incorporating grades to Table 5's models are reassuring. However, given the significant positive female gap in exam grades, it seems quite relevant to incorporate also the interaction "gender*exam grades." It may affect the coefficients related to promotion and gender.

Furthemore, I would expect individuals with higher grades to have higher likelihood to accept the job interview. The coefficient of exam grades is positive but non-significant. This might change when adding also the interaction gender*exam grades.

Regardless of this result, I think the regressions with exam grades should appear in the paper. Currently, the authors only provide them "upon request."

We included the additional regressions with the exam grades in the paper. We also added an interaction term gender*exam grades (see the new Table 5). We thank the reviewer for suggesting this potential interaction effect: we agree that this in principle could have affected our coefficients related to promotion and gender. However, none of the main results are affected by this.

2) In p. 23 the following sentence is unclear: "The results of this mediation analysis should be interpreted with care, because the mediating factors were observed among - not randomly assigned to - the participants in the experiment."

One clearer alternative would be:

"The results of this mediation analysis should be interpreted with care, because the mediating factors were observed - rather than randomly assigned- among the participants in the experiment."

We changed the sentence. We thank the reviewer for taking the time to make such concrete suggestions.

3) One of the references I suggested was Reuben, E., P. Sapienza, and L. Zingales. "Taste for competition and the gender gap among young business professionals, " rather than the one cited in the paper: Reuben, E., Sapienza, P., \& Zingales, L. (2015). Procrastination and impatience. Journal of Behavioral and Experimental Economics, 58, 63-76.

We changed that reference in the revised version of our paper. 